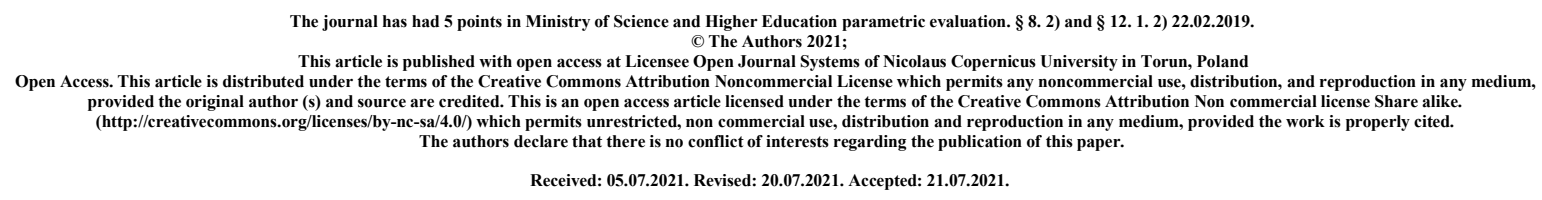

\title{
Pleiotropic effects of vitamin D3
}

Dominika Egierska

Affiliation Uniwersytet Medyczny im. Piastów Śląskich we Wrocławiu

Country

Poland

Bio Statement -

Principal contact for editorial correspondence.

Paulina Pietruszka

Affiliation Uniwersytet Medyczny im. Piastów Śląskich we Wrocławiu

Country Poland

Bio Statement -

Paulina Burzyńska

Affiliation Uniwersytet Medyczny im. Piastów Śląskich we Wrocławiu

Country

Poland

Bio Statement -

Izabela Chruścicka

Affiliation Uniwersytet Medyczny im. Piastów Śląskich we Wrocławiu Country Poland

Bio Statement -

Justyna Buchta

Affiliation Uniwersytet Medyczny im. Piastów Śląskich we Wrocławiu Country Poland

Bio Statement -

\begin{abstract}
Introduction: Vitamin D belongs to the group of fat-soluble vitamins. cholecalciferol (D3) and ergocalciferol (D2) are the most important forms. Vitamin D is associated with a regulatory role in calcium and phosphate metabolism. In recent years, there has been attention to its pleiotropic action.

Aim: The aim of the study was to present the general characteristics of vitamin D and explore its relation with polycystic ovary syndrome (PCOS), endometriosis, pain management, insulin resistance, influenza and chronic kidney disease (CKD).
\end{abstract}


Description: VDR receptor has been detected in the cells of the intestines, bones, kidneys, heart, brain, prostate, breast, ovaries, skin. In the ovaries, vit. D3 affects the production of progesterone, estradiol or estrone which suggest its important role in the folliculogenesis and ovulation. Women with PCOS have significantly lower levels of vitamin D3 compared to healthy women. It has been suggested that the deficiency of this vitamin may be related to infertility. Research show that vit. D3 may affect the mechanisms of the inflammatory and nocyceptive pain perception. A significant connection has also been found between vit. D3 and the metabolism of the adipose tissue and insulin secretion. Vitamin D3 deficiency may increase the risk of development of obesity and insulin resistance as well as CKD.

Summary: The observation of statistically significant correlation between the reduced level of vit. D3 and occurrence of numerous diseases indicates the need for further research to explain the mechanisms in which D3 deficiency may contribute to development of these diseases. This knowledge is important for the development of new prevention and treatment methods of the diseases mentioned in this article.

\section{Key words: Vitamin D3; cholecalciferol; calcitriol}

Vitamin D is a fat-soluble group that, in addition to controlling the intestinal absorption of calcium, magnesium and potassium, also exerts many other important biological effects. Vitamin D3 (cholecalciferol) and vitamin D2 (ergocalciferol) are particularly important for humans [1]. The main source of cholecalciferol is its synthesis in the deeper layers of the skin epithelium in a reaction dependent on solar radiation. Moreover, both cholecalciferol and ergocalciferol can be consumed with meals [2]. Vitamin D2 is mainly found in plant-based foods, while vitamin D3 is abundant in meat products.

Calcitriol, which is the active metabolite of vitamin D, due to its hydrophobicity may penetrate biological membranes and thereby can bind its receptor (VDR), which is located inside the nucleus of target cells. After binding to the receptor, calcitriol acts as a transcription factor that controls the expression of protein genes related, inter alia, to the absorption of calcium in the intestines [3]. VDR receptors are present in numerous tissues and organs, including the intestines, bones, heart, brain, prostate, and mammary gland. VDR activation in organs such as the intestines, bones, kidneys, and parathyroid glands is mainly responsible for the regulation of the concentration of calcium and phosphate in the blood [4].

Vitamin D deficiency is a worldwide problem, regardless of age, gender and race. In the Polish population, the deficiency of this vitamin was found in $90 \%$ of adults, children and adolescents [5]. 
Tab. 1. Comparison of recommendations regarding supplementation with calcium and vitamin D for Poland (2009), Central Europe (2013) and global recommendations for the prevention and treatment of deficiency rickets (2016) [5].

\begin{tabular}{|c|c|c|c|}
\hline & $\begin{array}{l}\text { Recommendations in } \\
\text { Poland (2009) }\end{array}$ & $\begin{array}{l}\text { Recommendations in } \\
\text { Central } \quad \text { Europe } \\
(2013)\end{array}$ & $\begin{array}{l}\text { Global } \\
\text { recommendations } \\
(2016)\end{array}$ \\
\hline \multicolumn{4}{|c|}{ Definition of vitamin d supply to serum $25(\mathrm{OH}) \mathrm{D}$ concentration $(1 \mathrm{ng} / \mathrm{ml}=2,5 \mathrm{nmol} / \mathrm{l})$} \\
\hline $\begin{array}{l}\text { Sufficient } \\
\text { concentration }\end{array}$ & $\begin{array}{l}\text { children and youth: } 20-60 \\
\mathrm{ng} / \mathrm{ml} \\
\text { adults and seniors } 30-80 \\
\mathrm{ng} / \mathrm{ml}\end{array}$ & $>30-50 \mathrm{ng} / \mathrm{ml}$ & $>20 \mathrm{ng} / \mathrm{ml}$ \\
\hline $\begin{array}{l}\text { Insufficient } \\
\text { concentration }\end{array}$ & Not defined & $20-30 \mathrm{ng} / \mathrm{ml}$ & $12-20 \mathrm{ng} / \mathrm{ml}$ \\
\hline $\begin{array}{l}\text { Deficit } \\
\text { concentration }\end{array}$ & $<10 \mathrm{ng} / \mathrm{ml}$ & $0-20 \mathrm{ng} / \mathrm{ml}$ & $<12 \mathrm{ng} / \mathrm{ml}$ \\
\hline $\begin{array}{l}\text { Toxic } \\
\text { concentration }\end{array}$ & Not defined & $>100 \mathrm{ng} / \mathrm{ml}$ & $>100 \mathrm{ng} / \mathrm{ml}$ \\
\hline \multicolumn{4}{|c|}{ Intake recommendations for vitamin $\mathrm{D}(40 \mathrm{IU}=1 \mu \mathrm{g})$} \\
\hline 0-6 months old & $400 \mathrm{IU} /$ day & $400 \mathrm{IU} /$ day & $400 \mathrm{IU} /$ day \\
\hline 6-12 months old & 400 IU/ day & 400-600 IU/ day & 400 IU/ day \\
\hline $2-18$ years old & $400 \mathrm{IU} /$ day & 600-1000 IU/ day & $600 \mathrm{IU} /$ day \\
\hline$>18$ years old & 800-1000 IU/ day & 800-2000 IU/ day & 600 IU/ day \\
\hline $\begin{array}{l}\text { Pregnancy and } \\
\text { lactation }\end{array}$ & 800-1000 IU/ day & $1500-2000 \mathrm{IU} /$ day & 600 IU/ day \\
\hline
\end{tabular}

The action of vitamin $\mathrm{D}$ is not limited to regulating the levels of calcium and phosphate in the blood. In recent years, several hundred human genes have been discovered whose expression is influenced by calcitriol. This compound supports the proliferation and differentiation of cells belonging to the immune system, induces apoptosis of cancer cells and slows their multiplication, increases the production of cathelicidin and beta-defensin, modulates the activity of lymphocytes, reduces the concentration of pro-inflammatory 
cytokines (Il-1, TNF alpha) while increasing the concentration of cytokines antiinflammatory, reduces renin secretion, inhibits angiogenesis, stimulates the synthesis of neurotrophic factors, inhibits the processes of fibrosis in the kidneys, has a strong immunomodulatory effect. Such a pleiotropic effect of vitamin D has initiated many observational studies that suggest a relationship between low vitamin D levels and an increased probability of the development of such diseases as, for example, cancer (especially of the colon, breast, ovary, prostate, pancreas, skin, brain, multiple myeloma, leukemia)., autoimmune diseases (eg multiple sclerosis, inflammatory bowel diseases, systemic lupus erythematosus), Addison's disease, Graves' disease, immune disorders, atherosclerosis, ischemic heart disease, psychiatric diseases, and neurodegenerative diseases [5].

Vitamin D3 and fertility

In the human body, vitamin D3 [calcitriol, $25(\mathrm{OH}) \mathrm{D}$ ] modulates the expression of over 3000 genes by stimulating the VDR receptor found in various tissues, including the organs of the reproductive system. This indicates an important function of vitamin D3 in the proper functioning of this system [6].

In the ovary, calcitriol stimulates the production of progesterone, estradiol or estrone [7]. In this organ, the presence of vitamin D3 was confirmed in the follicular fluid, and the expression of VDR in granular cells. This fact suggests that vitamin D3 may be important in folliculogenesis, but it has not yet been clearly confirmed. Scientists claim that, similarly to skin cells, in granular cells, vitamin D3 can stimulate the activity of aromatase, responsible for the conversion of androgens to estrogens, which would prove the key role of vitamin D3 in folliculogenesis and ovulation [6].

It is worth paying attention to the role of the endometrium as a non-renal site of vitamin D3 metabolism. It regulates the expression of endometrial receptivity markers, which play an important role in the process of embryo implantation. Studies on mice have shown that mutation of one of the factors, ie HOXA10, causes functional abnormalities of the uterus and the associated infertility [6], [7].

Animal studies show a key effect of vitamin D3 on fertility and litter size. Mice lacking the VDR gene are characterized by impaired folliculogenesis and ovulation, as well as reduced aromatase activity in the ovary [6].

Polycystic ovary syndrome (PCOS)

Polycystic ovary syndrome is a common endocrinopathy in women of reproductive age [7]. The characteristic symptoms are: [6]

- Increased production of ovarian and adrenal androgens

- Acne and hirsutism

- Irregular periods

- Ultrasound image of polycystic ovaries

- Insulin resistance

- Hyperinsulinemia

- Fertility disorders

More and more is said about the correlation between the occurrence of polycystic ovary syndrome and infertility and an increased frequency of miscarriages [6]. The observations carried out show that vitamin D is associated with various metabolic and reproductive features of PCOS, which suggests that it may be involved in the pathogenesis of the syndrome [8]. It is possible that these symptoms may be related to disturbances in calcium metabolism. These abnormalities are the cause of vitamin D3 deficiency and may inhibit the maturation of ovarian follicles [7]. 
Most women struggling with PCOS are overweight or obese, which is associated with lower levels of vitamin D3 in the plasma of these patients, mainly due to lipophilic vitamin sequestration in adipose tissue, as well as lower exposure of obese people to sunlight [8]. The results of studies carried out by Brzozowska et al. [7] showed a low concentration of $25(\mathrm{OH})$ $\mathrm{D}$ in the serum of women with PCOS, which suggests that vitamin D3 deficiency may be one of the factors predisposing to polycystic ovary syndrome. Similar conclusions were drawn by Voulgaris et al. [8], who observed that women with PCOS had significantly lower levels of vitamin D3 compared to healthy women. Additionally, among the female population with PCOS, obese women showed lower vitamin D levels than those who were overweight or lean.

Research aimed at determining the effectiveness of vitamin D supplementation in the prevention of PCOS and infertility is still ongoing, but the results so far are promising [7], [8]. Vitamin D regulates the body's calcium metabolism and thus indirectly influences the action of insulin by regulating intracellular calcium-dependent processes. Animal studies clearly show that vitamin D3 supplementation has a positive effect on the functioning of pancreatic beta cells responsible for insulin synthesis and increased tissue sensitivity to insulin [7].

\section{ENDOMETRIOSIS}

Endometriosis is a disease of unknown etiology characterized by the presence of endometrial tissue outside the uterine cavity [9]. Infertility is diagnosed in up to half of women suffering from endometriosis [6]. Research is ongoing to determine the causes of endometriosis. Currently, the most commonly accepted explanation for the development of this condition is the combination of retrograde menstruation, a situation in which blood flows back into the pelvis instead of the vagina during menstruation; defective immune mechanisms that prevent the removal of abnormal tissue from the peritoneal cavity and changes in the peritoneal environment that are responsible for stimulating cell growth [10].

Due to the insufficient knowledge of the factors responsible for the occurrence of endometriosis, the treatment that would demonstrate proven efficacy is unknown [10]. It is assumed that dairy foods and some nutrients can modulate inflammatory and immune factors, which are modified in women with endometriosis [9]. Due to its anti-inflammatory and immunomodulatory properties, numerous studies have been conducted in recent years to determine the effect of vitamin D deficiency on the occurrence of endometriosis [6].

Disease progression depends on the degree of impaired cellular immunity and the proliferative effects of cytokines. It has been shown that immune cells in the peritoneal fluid of women with endometriosis secrete cytokines, growth factors and angiogenic factors that stimulate implantation and proliferation of abnormally located endometrial tissue and local angiogenesis. Akyol et al. [10] conducted an experiment involving the supplementation of vitamin D3 and omega-3 polyunsaturated fatty acids (omega-3 PUFA) on a group of 30 female rats. In the group of rats administered omega-3 PUFA, a significant decrease in the amount of factors such as Interleukin-6, TNF-alpha, VEGF and a significant decrease in the amount of ectopic endometrium was shown. In the group of individuals administered vitamin $\mathrm{D}$, only a decrease in the concentration of interleukin-6 and a slight decrease in the amount of ectopic tissue were observed. The results of the study show an ambiguous effect of vitamin D supplementation on the course of endometriosis.

American scientists have come to different conclusions. In 2012, Harris et al. [9] presented the results of studies that were carried out on a group of 70556 premenopausal women. Within 14 years, 1,385 cases of laparoscopically confirmed endometriosis were recorded in this group. Observations indicate a positive effect of dairy consumption in reducing the risk of endometriosis. Moreover, women who consumed more than 3 servings of dairy products per day had an $18 \%$ lower risk of being diagnosed with endometriosis than women who consumed 2 servings of dairy products per day. Moreover, the predicted $25(\mathrm{OH})$ 
D plasma level was inversely related to the incidence of endometriosis. Total intake of calcium and vitamin D (including supplements) and intake of calcium and vitamin D exclusion from dairy sources have not been shown to be associated with endometriosis, but intake of calcium and vitamin D from food was inversely proportional to the incidence of endometriosis. However, the risk-reducing effect of endometriosis has been reduced by consuming foods rich in calcium and vitamin $\mathrm{D}$ with milk. The authors conclude that the findings in the above-mentioned study suggest that higher predicted plasma $25(\mathrm{OH}) \mathrm{D}$ levels and higher consumption of dairy products are associated with a reduced risk of endometriosis.

\section{Vitamin D and pain management}

According to the International Society for the Study of Pain, the definition of pain is as follows: it is an unpleasant sensory and emotional experience associated with actual or potential tissue damage, or related to the perception of such damage. Physical pain is divided into nociceptive, inflammatory and neuropathic pain. Psychological pain, also known as existential pain, was also distinguished [11]. Nociceptive pain can be treated with opioids and non-steroidal anti-inflammatory drugs (NSAIDs), which are also used together with steroid drugs to treat inflammatory pain. On the other hand, in the treatment of neuropathic pain, subgroups of antiepileptic drugs and tricyclic antidepressants are used. Research shows that vitamin $\mathrm{D}$ can influence the mechanisms of inflammatory and nociceptive pain perception. [12], [13], [14], [15]. This is due to the fact that receptors for vitamin D (VDR) are found in the membranes of many cells, including in: skin, bones, muscles (where pain receptors are also present), endocrine glands and cells of the immune system, therefore it is justified to say that the level of vitamin D may influence the perception of pain [16].

Research confirms that vitamin D has an anti-inflammatory effect on the immune system, which is presented in the table below:

Tab. 2. Prepared on the basis of Tab. 1 in Helde-Frankling M, Björkhem-Bergman L. Vitamin D in pain management. Int. J. Mol. Sci. 2017; 18 (10): 1-9 [11].

The effect of vitamin $\mathrm{D}$ on the immune system

\begin{tabular}{|l|c|}
\hline Antimicrobial Peptides (AMP) & $\uparrow$ \\
\hline Inflammation & $\downarrow$ \\
\hline Th1 lymphocytes & $\downarrow$ \\
\hline Th17 lymphocytes & $\downarrow$ \\
\hline Th2 lymphocytes & $\uparrow$ \\
\hline Treg lymphocytes (regulatory) & $\uparrow$ \\
\hline Prostaglandin E2 & $\downarrow$ \\
\hline TNF $\alpha$ & $\downarrow$ \\
\hline Leukotrienes B 4 & $\downarrow$ \\
\hline
\end{tabular}

As the table shows, vitamin D influences the cellular response by reducing the level of pro-inflammatory Th1 and Th17 lymphocytes, and promotes the proliferation of Th2 and 
Treg lymphocytes. It also inhibits the synthesis of prostaglandin II (PGE2) by fibroblasts, which is also an important factor in the inflammatory process.

On the basis of published randomized clinical trials, it can be concluded that patients suffering from chronic pain and supplementing with vitamin D experience pain less severe than patients who were given a placebo [11]. In contrast, interventional studies have shown that vitamin D supplementation in the amount of 50,000 IU / week can prevent the development of myalgia (muscle pain) in patients treated with statins [17], [18]. In the years 2008-2010, a randomized semi-crosswise controlled trial was carried out in the Netherlands, involving 84 people - immigrants from eastern countries, reporting to a doctor due to musculoskeletal pain. Vitamin D deficiency was found in all subjects - its serum level was $<50 \mathrm{mmol} / \mathrm{L}$. The study showed a slight positive effect of vitamin D supplementation for 6 weeks in high doses on pain sensation in the subjects. Several hypotheses regarding the mechanism of action of vitamin D are associated with this musculoskeletal pain relieving effect: rapid non-genomic effect on muscle cell metabolism, slow genomic effect on muscle fiber growth, and non-specific effect on the central or peripheral nervous system [19]. It is worth emphasizing that the positive effect of vitamin D on the perception of pain has been proven only in people with a deficiency of this vitamin. Suggested amount of supplemented dose for patients with serum 25-OHD level $<30 \mathrm{nmol} / \mathrm{L}$ dose $4000 \mathrm{IU} /$ day for min. 3 months or until the 25-OHD level is $>50 \mathrm{nmol} / \mathrm{L}$. This dose is considered effective and safe at the same time [11].

\section{Vitamin D and insulin resistance}

Insulin resistance and type II diabetes are diseases that affect more and more people around the world. According to the WHO, about 15 million people worldwide suffer from type 2 diabetes mellitus (T2DM), and by 2025 this number may double. The following disorders lead to the development of insulin resistance and T2DM: defects in the functioning of insulin signaling pathways, dysfunction of pancreatic $\beta$ cells and systemic inflammation [20], [21], [22]. Since a link between vitamin D deficiency and the pathogenesis of many diseases, including metabolic diseases, has been demonstrated, such an influence on the development of insulin resistance has also been suggested.

Numerous clinical studies have shown a positive effect of vitamin D supplementation on metabolic parameters important in the development and course of insulin resistance and diabetes, e.g. lowering the level of total cholesterol, LDL and triglycerides, reducing the level of glycated hemoglobin, as well as lowering the value of the HOMA-IR index, which is an indicator of the level of insulin resistance [20], [22]. Vitamin D receptor (VDR) was detected in pancreatic $\beta$ cells and in adipose tissue (adipocytes) [23]. Adipose tissue is a large reservoir of vitamin D and secretes cytokines involved in the development of inflammation, which can lead to the development of obesity. It has been suggested that an important factor in the relationship between abdominal obesity and diabetes is vitamin D deficiency [23], [24].

So how can vitamin $\mathrm{D}$ interact with pancreatic $\beta$ cells? Of course, this is done by interacting with the VDR present in the cell membrane, which activates signaling pathways which in turn affect the flow and elevation of intracellular calcium levels, which in turn stimulates exocytosis of insulin-containing vesicles. Calcitriol deficiency leads to the accumulation of calcium ions extracellularly, and consequently to a decrease in GLUT4 activity and the development of insulin resistance [20], [25].

Another aspect worth considering is the correlation of vitamin D with adipose tissue due to the fact that abdominal obesity is a risk factor for the development of insulin resistance and type II diabetes. First, does vitamin D influence its development, i.e. adipogenesis? Studies have shown that VDR receptors are abundantly present in the cell membrane of adipocytes in the early stage of adipogenesis, and their level decreases with the progress of 
this process [26], [27]. However, researchers disagree on whether vitamin D promotes or inhibits adipogenesis. It has been shown that calcitriol can inhibit adipogenesis by inhibiting the expression of PPAR $\gamma$ (receptors activated by peroxisome proliferators) and C / EBP $\alpha$ transcription factors playing an important role in the process of adipogenesis [20], [26]. Therefore, this issue requires further research [20], [27].

Vitamin influences the apoptosis of mature adipocytes. When a calcitriol molecule binds to the VDR in the membrane of a mature cell, it stimulates voltage-dependent as well as voltage-independent calcium channels. This results in an influx of $\mathrm{Ca} 2+$ into the adipocyte and the release of calcium ions from the endoplasmic reticulum through ryanodine channels and the inositol triphosphate receptor, which acts as a calcium channel. In this way, an elevated intracellular calcium level activates calpain-calcium-dependent proteases and thus the apoptosis process. Therefore, it can be concluded that vitamin D supports the degradation of adipose tissue [20], [23]. Vitamin D is also a factor that inhibits the secretion of proinflammatory cytokines (IL-1 $\beta$, IL-6, IL-8, TNF- $\alpha$, CRP) by adipose tissue, which may lead to the development of obesity [28], [29]. In the states of vitamin D deficiency, the abovedescribed processes are disturbed, the metabolism of adipose tissue is not controlled, obesity associated with inflammation develops, which is an important factor in the development of insulin resistance.

To sum up, vitamin D exerts a significant influence on the $\beta$-cells of the pancreas and adipose tissue, the proper functioning of which determines the proper functioning of metabolism. Calcitriol deficiencies may lead to imbalance and the development of insulin resistance. [20].

Vitamin D and the flu

Influenza is an important and common infectious disease. It is estimated to be responsible for 250-500 thousand deaths annually. It poses a particular threat to the elderly population [30].

Via the vitamin D receptor (VDR), vitamin D can modulate the response of the innate and acquired immune system [31].

Recently, immune cells have been shown to possess a VDR, which allows them to metabolize calcitriol, which may mean that this vitamin plays an important role in the immune response. Activated $\mathrm{B}$ and $\mathrm{T}$ lymphocytes have the ability to convert the inactive form of vitamin D (25-OH-D3) into the active form - calcitriol (1,25-OH-D3) [32]. Endothelial cells that line the upper and lower airways exhibit similar properties. 1,25-OHD3 acts on immune cells in an autocrine, paracrine and intracrine manner [31].

In addition, vitamin $\mathrm{D}$ helps maintain the tightness of intercellular connections closing, gap and adjacent. The integrity of these connections is disturbed by viral infections [33].

Vitamin D also strengthens and strengthens the innate cellular immunity. Through 1,25-cholecalciferol and defenses it induces the action of antimicrobial peptides, e.g. human cathelicidin LL-37. The group of cathelicidins is characterized by direct antibacterial, antiviral and antifungal activity. Additionally, they have the ability to destroy pathogens, disrupting the integrity of their cell membranes and neutralizing the action of endotoxins secreted by them [34].

The innate immune system synthesizes pro-inflammatory and anti-inflammatory cytokines in response to viral infections. By administering vitamin D, it is possible to reduce the expression of pro-inflammatory cytokines, e.g. IL-2 and IFN- $\gamma$ (produced e.g. by Th1 helper lymphocytes) and increase the expression of anti-inflammatory cytokines e.g. IL-4 and IL-10 (produced e.g. by Th2 helper lymphocytes) [35]. Moreover, it induces T regulatory cells, which inhibits inflammatory processes [36]. 
Urashima et al. [37]. studied the incidence of influenza A virus among schoolchildren. The studies were conducted in the winter period - from December 2008 to March 2009. The results were as follows: symptoms of virus infection occurred in 18 out of 167 children in the study group (daily supplementation of $1200 \mathrm{IU}$ of vitamin D) and in 31 out of 167 in the control group ( taking a placebo). It should be noted that much better results were obtained for the group of children diagnosed with respiratory diseases and taking vitamin D.

Moreover, the meta-analysis by Bergman et al. [38] from 2013 indicates the protective role of vitamin D in infectious diseases of the respiratory tract. The authors indicate that its supplementation once a day is the most effective. Due to the heterogeneity of the included studies, the researchers emphasize that the obtained results should be interpreted with caution.

Vaccination is a commonly used form of flu prevention, but its effectiveness is not satisfactory, estimated at 59\% [39].

Vitamin D has the aforementioned immunomodulatory effects and may have an influence on the immunogenic response to influenza vaccination. On this basis, it has been suggested that vitamin D deficiency may contribute to the low effectiveness of influenza vaccination [39].

Ming-Dar Lee et al. [30] in their meta-analysis they compared 10 studies dealing with this problem. Researchers found no association between vitamin D deficiency and decreased immune response to influenza vaccine. However, they suggested that the occurrence of this correlation may differ depending on the virus strain. The authors emphasize the need for further research in this direction.

Based on current research, it can be concluded that vitamin D is one of the important factors influencing the complex immune response. Therefore, regular evaluation and maintenance of adequate vitamin D levels is advisable, especially in the elderly and child population. However, a review of the literature does not provide a clear answer regarding the role of vitamin D in the prevention and treatment of viral infections [31].

\section{Vitamin D and Chronic Kidney Disease (CKD)}

Calcitriol (1.25-cholecalciferol), the active form of vitamin D3, is responsible for many important functions in CKD patients: it increases the absorption of calcium and phosphate in the gastrointestinal tract, enhances the reabsorption of calcium in the renal tubules and inhibits the secretion of parathyroid hormone from the parathyroid glands. Moreover, proper supply of the native (hepatic form) vitamin D (25-OH-D3 / calcidiol) in the form of ergocalciferol (vitamin D2) and cholecalciferol (vitamin D3) is required for the proper synthesis of calcitriol in the proximal renal tubules [40].

In patients with chronic kidney disease, the levels of hyperphosphate hormone FGF23 are increased to compensate for phosphate retention. Moreover, it inhibits the expression of $1 \alpha$-hydroxylase and induces the expression of 24-hydroxylase, which is responsible for the degradation of 1,25-cholecalciferol. Additionally, in patients with $\mathrm{CKD}$, a progressive decrease in the concentration of 1.25-cholecalciferol was observed, in direct proportion to the decrease in the glomerular filtration rate (GFR) [41].

One theory assumes that it may be caused by a reduction in the number of renal glomeruli along with proximal tubules, whose task is the reabsorption of calcidiol with its subsequent enzymatic hydroxylation with the participation of $1 \alpha$-hydroxylase to the active form of vitamin D3 [40].

The second hypothesis explains the decreased concentration of the active form of vitamin D3 as a result of substrate deficiency (insufficient serum 25-OH-D3 concentration). The reason for this may be a decrease in the cutaneous synthesis of pre-vitamin D3 due to increased skin pigmentation or a decrease in exposure to solar radiation (UV-B). It was also 
noted that the use of a low-protein diet to reduce the effect of phosphates may lead to an increase in the substrate deficit as well as may cause increased loss of vitamin D-binding proteins (VDBP) with urine in patients with nephrotic syndrome [40].

In people suffering from $\mathrm{CKD}$, vitamin $\mathrm{D}$ deficiency is a widespread problem, which is associated with albuminuria, faster disease progression and increased mortality regardless of the cause [42]. González et al. [43] in their study report that $97 \%$ of hemodialysis patients have an inappropriate (too low) serum concentration of 25-OH-D3.

E. Çankaya et al. [44] On the basis of the performed studies, they observed that the serum concentration of 25-OH-D3 in patients undergoing peritoneal dialysis and hemodialysis was lower compared to patients after kidney transplantation.

Reduced calcitriol synthesis leads to hypocalcemia and secondary hyperparathyroidism, which can lead to secondary osteoporosis. Low 25-OH-D3 levels are associated with increased metabolic changes in bones, which results in a decrease in bone density in CKD and dialysis patients. Calcidiol deficit leads to muscle weakness and an increased risk of falls [45]. Moreover, insulin resistance, ventricular hypertrophy and atherosclerosis have been observed in patients [46].

Liu et al. [47] in their work, they note that low vitamin D levels in people undergoing peritoneal dialysis may lead to cognitive impairment.

Currently, in the case of vitamin D deficiency in patients with chronic kidney disease, the preferred combination treatment leads to a reduction in serum phosphate levels, improvement of the negative $\mathrm{Ca} 2+$ balance and inhibition of parathyroid hormone secretion (in the case of secondary hyperparathyroidism) [48].

Therapy is started with the administration of phosphate binders, such as sevelamer, calcium salts or iron preparations (e.g. ferric citrate).

Then, in order to correct the negative calcium balance, $1 \alpha$-hydroxylated analogues of vitamin $\mathrm{D}$ are used - calcitriol [1,25-OH-D3], paricalcitol [1,25-OH-19-nor-D2], doxercalciferol [1-OH-D2] , alpha-calcidiol [1-OH-D3] and used only in Japan - maxacalcitol [22-oxa-1,25-OH-D3]. To lower the level of parathyroid hormone in the blood, a calcimimetic drug, cinacalcet, is administered. Clinical trials have shown that lower proteinuria has been observed in patients treated with paricalcitol [49], [50].

Pilz et al. [51] in their meta-analysis from 2011 showed that the level of 25-OH-D3 above $10 \mathrm{ng} / \mathrm{ml}$ reduces the risk of death by $14 \%$. Whereas Jean et al. [52] in 2010, they reported that the risk of mortality increased by $30 \%$ when serum $25-\mathrm{OH}-\mathrm{D} 3$ levels were below $18 \mathrm{ng} / \mathrm{ml}$.

Low vitamin D levels, common in CKD patients, are a significant risk factor for the development of many abnormalities and metabolic disorders. Its identification and treatment improve the efficiency of the active form of vitamin D3 synthesis, which helps to avoid complications related to secondary hyperparathyroidism [40].

\section{Bibliography}

[1] Sajkowska-Kozielewicz JJ, Paradowska K. Witamina D - składnik o wielostronnym działaniu. Herbalism. 2016; 1(2): 35-58. https://doi.org/10.12775/herb.2016.003

[2] Spiro A, Buttriss JL. Vitamin D: An overview of vitamin D status and intake in Europe. Nutr. Bull. 2014; 39(4): 322-350. https://doi.org/10.1111/nbu.12108

[3] Christakos S, Dhawan P, Verstuyf A, et al. Vitamin D: Metabolism, molecular mechanism of action, and pleiotropic effects. Physiol. Rev. 2015; 96(1): 365-408. https://doi.org/ 10.1152/physrev.00014.2015

[4] Bikle DD. Vitamin D metabolism, mechanism of action, and clinical applications. Chem. Biol. 2014; 21(3): 319-329. http://dx.doi.org/10.1016/j.chembiol.2013.12.016

[5] Rusinska A, Płudowski P, Walczak M, et al. Vitamin D supplementation guidelines 
for general population and groups at risk of vitamin $\mathrm{D}$ deficiency in PolandRecommendations of the Polish society of pediatric endocrinology and diabetes and the expert panel with participation of national specialist consultants and representatives of scientific societies-2018 update. Front. Endocrinol. (Lausanne). 2018; 9(5): 1-24. https://doi.org/10.3389/fendo.2018.00246

[6] Herian M, Grzesiak M. Rola witaminy D i jej metabolitów w metabolizmie wapniowo-fosforanowym. Kosmos. 2017; 30(4): 515-549.

[7] Brzozowska M, Karowicz-Bilińska A. Rola niedoboru witaminy D w patofizjologii zaburzeń występujących w zespole policystycznych jajników. Ginekol. Pol. 2013; 84(6): 456-460.

[8] Voulgaris N, Papanastasiou L, Piaditis G, et al. Vitamin D and aspects of female fertility. Hormones. 2017; 16(1): 5-21. https://doi.org/10.14310/horm.2002.1715

[9] Harris HR, Chavarro JE, Malspeis S, et al. Original Contribution Dairy-Food, Calcium, Magnesium, and Vitamin D Intake and Endometriosis: A Prospective Cohort Study. American Journal of Epidemiology. 2013; 177(5): 420-430. https://doi.org/10.1093/aje/kws247

[10] Akyol A, Simsek M, Ilhan R, et al. Efficacies of vitamin D and omega-3 polyunsaturated fatty acids on experimental endometriosis. Taiwan. J. Obstet. Gynecol. 2016; 55(6): 835-839. https://doi.org/ 10.1016/j.tjog.2015.06.018

[11] Helde-Frankling M, Björkhem-Bergman L. Vitamin D in pain management. Int. J. Mol. Sci. 2017; 18(10): 1-9. https://doi.org/10.3390/ijms 18102170

[12] Bergman P, Sperneder S, Höijer J, et al. Low Vitamin D levels are associated with higher opioid dose in palliative cancer patients-results from an observational study in Sweden. PLoS One. 2015; 10(5): 1-11. https://doi.org/10.1371/journal.pone.0128223

[13] Gendelman O, Itzhaki D, Makarov S, et al. A randomized double-blind placebocontrolled study adding high dose Vitamin D to analgesic regimens in patients with $\begin{array}{lllll}\text { musculoskeletal } & \text { pain. } & \text { Lupus. } & \text { 2015; } & \text { 24(4-5): }\end{array}$ https://doi.org/10.1177/0961203314558676

[14] Wepner F, Scheuer R, Schuetz-Wieser B, et al. Effects of vitamin D on patients with fibromyalgia syndrome: A randomized placebo-controlled trial. Pain. 2014; 155(2): 261-268. http://dx.doi.org/10.1016/j.pain.2013.10.002

[15] Gatenby P, Lucas R, Swaminathan A. Vitamin D deficiency and risk for rheumatic diseases: An update. Curr. Opin. Rheumatol. 2013; 25(2): 184-191. https://doi.org/10.1097/BOR.0b013e32835cfc16

[16] Frigstad SO, Høivik ML, Jahnsen J, et al. Pain severity and vitamin D deficiency in IBD patients. Nutrients. 2020; 12(1): 1-12. https://doi.org/10.3390/nu12010026

[17] Khayznikov M., Hemachrandra K., Pandit R., et al. Statin Intolerance Because of Myalgia, Myositis, Myopathy, or Myonecrosis Can in Most Cases be Safely Resolved by Vitamin D Supplementation. North American Journal of Medical Science. 2015; 7(3): 86-93. https://doi.org/10.4103/1947-2714.153919

[18] Glueck CJ, Budhani SB, Masineni SS, et al. Vitamin D deficiency, myositismyalgia, and reversible statin intolerance. Curr. Med. Res. Opin. 2011; 27(9): 1683-1690. https://doi.org/10.1185/03007995.2011.598144

[19] Schreuder F, Bernsen RMD, van der Wouden JC. Vitamin D supplementation for nonspecific musculoskeletal pain in non-western immigrants: A randomized controlled trial. Ann. Fam. Med. 2012; 10(6): 547-555. https://doi.org/10.1370/afm.1402

[20] Szymczak-Pajor I, Śliwińska A. Analysis of association between vitamin D deficiency and insulin resistance. Nutrients. 2019; 11(4): 794. https://doi.org/10.3390/nu11040794

[21] Wang H, Weiwen C, Dongqing L, et al. Vitamin D and chronic diseases. Aging Dis. 2017; 8(3): 346-353. https://doi.org/10.14336/AD.2016.1021 
[22] Tao S, Yuan Q, Mao L, et al. Vitamin D deficiency causes insulin resistance by provoking oxidative stress in hepatocytes. Oncotarget. 2017; 8(40): 67605-67613. https://doi.org/10.18632/oncotarget.18754

[23] Abbas MA. Physiological functions of Vitamin D in adipose tissue. J. Steroid Biochem. Mol. Biol. 2017; 165: 369-381. https://doi.org/10.1016/j.jsbmb.2016.08.004

[24] Li YX, Zhou L. Vitamin D deficiency, obesity and diabetes. Cell. Mol. Biol. 2015; 61(3): 35-38. https://doi.org/10.14715/cmb/2015.61.3.8

[25] Altieri B, Grant WB, Casa SD, et al. Vitamin D and pancreas: The role of sunshine vitamin in the pathogenesis of diabetes mellitus and pancreatic cancer. Crit. Rev. Food Sci. Nutr. 2017; 57(16): 3472-3488. https://doi.org/10.1080/10408398.2015.1136922

[26] Nimitphong H, Park E, Lee MJ, et al. Vitamin D regulation of adipogenesis and adipose tissue functions. Nutrition research and practice. 2020; 14(6): 553-567. https://doi.org/10.4162/nrp.2020.14.6.553

[27] Chang E, Kim Y. Vitamin D decreases adipocyte lipid storage and increases NADSIRT1 pathway in 3T3-L1 adipocytes. Nutrition. 2016; 32(6): 702-8. https://doi.org/10.1016/j.nut.2015.12.032

[28] Li B, Baylink DJ, Deb C, et al. 1,25-Dihydroxyvitamin D3 Suppresses TLR8 Expression and TLR8-Mediated Inflammatory Responses in Monocytes In Vitro and Experimental Autoimmune Encephalomyelitis In Vivo. PLoS One. 2013; 8(3): e58808. https://doi.org/10.1371/journal.pone.0058808

[29] Jean G, Souberbielle JC, Chazot C. Vitamin D in Chronic Kidney Disease and Dialysis Patients. Nutrients. 2017; 9(4): 328. https://doi.org/10.3390/nu9040328.

[30] Lee M, Lin CH, Lei WT, et al. Does Vitamin D Deficiency Affect the Immunogenic Responses to Influenza Vaccination? A Systematic Review and Meta-Analysis. 2018; 25: 1 12. https://doi.org/10.3390/nu10040409

[31] Gruber-bzura BM. Vitamin D and Influenza- Prevention or Therapy?. Int. J. Mol. Sci. 2018; 19(8): 2419. https://doi.org/10.3390/ijms19082419

[32] Vanherwegen A-S, Gysemans C, Mathieu C. Regulation of Immune Function by Vitamin D and Its Use in Diseases of Immunity. Endocrinology and Metabolism Clinics of North America, 2017; 46(4): 1061-1094. https://doi.org/10.1016/j.ecl.2017.07.010

[33] Rondanelli M, Miccono A, Lamburghini S, et al. Self-Care for Common Colds: The Pivotal Role of Vitamin D, Vitamin C, Zinc, and Echinacea in Three Main Immune Interactive Clusters (Physical Barriers, Innate and Adaptive Immunity) Involved during an Episode of Common Colds-Practical Advice on Dosages and on the Time to Take These Nutrients/Botanicals in order to Prevent or Treat Common Colds. Evidence-Based Complementary and Alternative Medicine. 2018; 2018: 5813095. https://doi.org/10.1155/2018/5813095

[34] Grant WB, Lahore H, McDonnell SL, et al. Evidence that vitamin d supplementation could reduce risk of influenza and covid-19 infections and deaths. Nutrients. 2020; 12(4): 119. https://doi.org/10.3390/nu12040988

[35] Gombart AF, Pierre A, Maggini S. A Review of Micronutrients and the Immune System - Working in Harmony to Reduce the Risk of Infection. Nutrients. 2020; 12(1): 236. https://doi.org/10.3390/nu12010236

[36] Zdrenghea MT, Makrinioti H, Bagacean C, et al. Vitamin D modulation of innate immune responses to respiratory viral infections. Reviews in medical virology. 2017; 27(1): e1909. https://doi.org/10.1002/rmv.1909

[37] Urashima M, Segawa T, Okazaki M, et al. Randomized trial of vitamin D supplementation to prevent seasonal influenza A in schoolchildren. Am. J. Clin. Nutr. 2010; 91(5): 1255-1260. https://doi.org/10.3945/ajcn.2009.29094

[38] Bergman P, Lindh AU, Bjorkhem-Bergman L, et al. Vitamin D and Respiratory Tract 
Infections: A Systematic Review and Meta-Analysis of Randomized Controlled Trials. PLOS ONE. 2013; 8(6): e65835. https://doi.org/10.1371/journal.pone.0065835

[39] Osterholm MT, Kelley NS, Sommer A. Belongia EA. Efficacy and effectiveness of influenza vaccines: a systematic review and meta-analysis. Lancet Infect. 2012; 12(1): 36-44. https://doi.org/10.1016/S1473-3099(11)70295-X

[40] Restrepo VCA, Aguirre AJV. Vitamin D in patients with chronic kidney disease stages 2-5. Colombia Médica. 2016; 47(3): 160-166. https://doi.org/10.2510/colomb.med..v50i1.4444

[41] Kaur G, Singh J, Kumar J. Vitamin D and cardiovascular disease in chronic kidney disease. Pediatr Nephrol. 2019; 34(12): 2509-2522. https://doi.org/10.1007/s00467-0184088-y

[42] Gois PHF, Wolley M, Ranganathan D, et al. Vitamin D deficiency in chronic kidney disease: Recent evidence and controversies. Int. J. Environ. Res. Public Health. 2018; 15(8): 1-16. https://doi.org/

[43] Gonzales EA, Sachdeva A, Oliver DA, et al. Vitamin D Insufficiency and Deficiency in Chronic Kidney Disease. American Journal of Nephrology. 2004; 24(5): 503-510. https://doi.org/10.1159/000081023

[44] Cankaya E, Bilen Y, Keles M, et al. Comparison of Serum Vitamin D Levels Among Patients With Chronic Kidney Disease, Patients in Dialysis, and Renal Transplant Patients. Transplantation Proceedings. 2015; 47(5): 1405-1407. https://doi.org/10.1016/j.transproceed.2015.04.036

[45] Jean D, Souberbielle JC, Chazot C. Vitamin D in Chronic Kidney Disease and Dialysis Patients. Nutrients. 2017; 9(4): 1-15. https://doi.org/10.3390/nu9040328

[46] Lai S, Coppola B, Dimko M, et al. Vitamin D deficiency, insulin resistance, and ventricular hypertrophy in the early stages of chronic kidney disease. Ren. Fail. 2014; 36(1): 58-64. https://doi.org/10.3109/0886022X.2013.832308

[47] Liu G, Pi H, Hao L, et al. Vitamin D Status Is an Independent Risk Factor for Global Cognitive Impairment in Peritoneal Dialysis Patients. PLoS ONE. 2015; 10(12): 1-13. https://doi.org/10.1371/journal.pone.0143782

[48] Zand L, Kumar R, Clinic M. The Use of Vitamin D Metabolites and Analogs in the Treatment of Chronic Kidney Disease. Endocrinol Metab Clin North Am. 2017; 46(4): 9831007. https://doi.org/10.1016/j.ecl.2017.07.008

[49] Lin Y-C, Chang Y-H, Yang S-H, et al. Update of pathophysiology and management of diabetic kidney disease. Journal of the Formosan Medical Association 2018; 117(8): 662675. https://doi.org/10.1016/j.jfma.2018.02.007

[50] Ekart R, Bevc S, Hojs R, et al. Proteinuria and Albuminuria During and After Paricalcitol Treatment in Chronic Kidney Disease Patients. The Journal of Clinical Pharmacology 2016; 56(6): 761-768. https://doi.org/10.1002/jcph.660

[51] Pilz S, Iodice S, Zittermann A, et al. Vitamin D Status and Mortality Risk in CKD: A Meta-analysis of. YAJKD. 2011; 58(3): 374-382. https://doi.org/10.1053/j.ajkd.2011.03.020

[52] Jean G, Lataillade D, Genet L, et al. Impact of Hypovitaminosis D and Alfacalcidol Therapy on Survival of Hemodialysis Patients: Results from the French ARNOS Study. Nephron Clin Pract 2011; 118(2): 204-210. https://doi.org/10.1159/0003215 